Session 2357

\title{
Redesigning a First-Year, First Semester Introductory IE Course to Use Active and Cooperative Learning
}

\author{
Manuel D. Rossetti, Ph.D. P. E., Merrisa Purnomo \\ University of Arkansas
}

\begin{abstract}
Active and cooperative learning methods recognize that the passive model of the typical college lecture does not work for many students. Instead, active and cooperative learning focuses on the premise that the students can learn best by doing and working with each other. Traditionally structured class periods imply that students listen to a professor lecture for about an hour. Cooperative learning can replace some of that lecture time with methods designed to get students actively involved during the class period. This paper presents the use of active and cooperative learning techniques applied to a first-year, first semester of principles of industrial engineering course. In this course, students are introduced to engineering problem solving, engineering design, and industrial engineering topic areas. In addition, this course provides introductory skills in computer technology and provides an opportunity for first-year students to get acclimated to the university within a supportive environment. Tips and examples for how to transform a standard lecture into a lecture based on cooperative exercises are given and the authors' experiences with these techniques are detailed. Examples include introductory coverage of quality control, engineering economics, material handling, manufacturing systems, and methods analysis. In addition, potential projects for the course will be discussed.
\end{abstract}

\section{Introduction}

This paper discusses how to implement active and cooperative learning methods within a firstyear, first semester Industrial Engineering course. Active and cooperative learning methods recognize that the passive model of the typical college lecture does not work for many students. Instead, active and cooperative learning is based on the premise that students can learn best by doing and working with each other. Active learning involves four major elements: talking/listening, writing, reading, and reflecting. (Meyers and Jones (1993)). Cooperative learning involves active group work that involves building interdependence, accountability, collaborative skills, and reflection. Reflection is achieved by students teaching and explaining material to each other, and by self/group evaluation. More detail on active and collaborative learning techniques can be found at reference [2] and [8].

Active and cooperative learning has been proven to be an effective technique for enhancing student learning and improving student retention through its supportive structured group work. An extensive analysis by Johnson, Johnson, and Smith (1998) revealed that cooperative learning has been extensively analyzed and proven to be effective. Their meta-analysis of the educational 
literature on cooperative learning found that there have been over 500 experimental and 100 correlational studies conducted involving both children and adults. They concluded that overwhelming evidence exists that cooperative learning leads to improvements in achievement, retention, critical thinking, and teamwork skills. Felder et al. (1998) describes a longitudinal study involving the effectiveness of various instructional methods and their relationship to learning styles. In the study, the experimental group outperformed the control group on a number of measures. Felder et al. (1998) concluded that retention was improved, preparation for upper level material improved, higher critical skills were improved, and computer based problem solving skills improved.

In traditionally structured class periods, students listen to a professor lecture for about an hour. Cooperative learning can replace some of that lecture time with methods designed to get students actively involved during the lecture period. Figure 1 illustrates the concept of breaking up the lecture into small group activities sandwiched by lectures. This method allows the instructor the flexibility of using activities and ensuring that material can be appropriately covered. An important aspect of using this approach is having well defined active learning handouts for the students. In this paper, we will give examples of these handouts for the Principles of Industrial Engineering course. The cooperative learning lecture is also described in Rossetti and Nembhard (2000). We have also utilized these techniques in other industrial engineering courses such as simulation (Rossetti (1997) and Rossetti and Nembhard (1998), quality management, database, and probability/statistics.

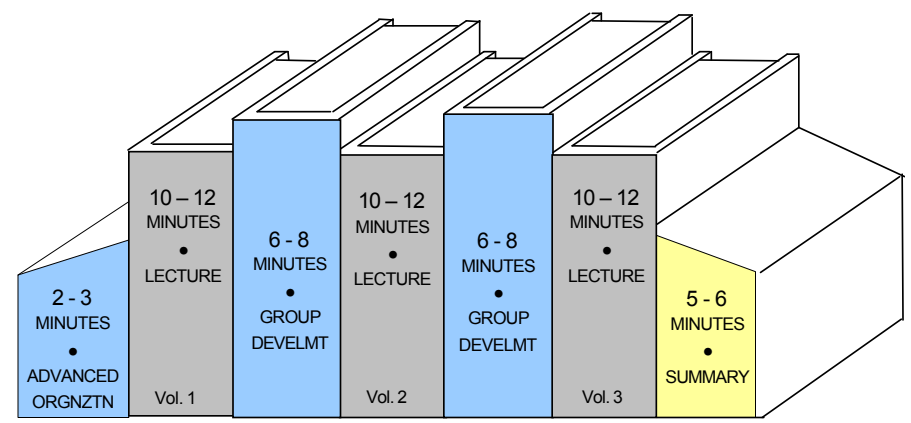

Figure 1. The cooperative learning lecture

Active and cooperative learning can be especially effective in a first-year engineering curriculum. Smith (1993) describes the development of an introductory engineering course that emphasizes active and cooperative learning. The course is centered on model building as a process that students can and should be actively engaged in. The course is supported by a text, Starfield et al. (1994), that emphasizes the active learning of modeling. LeBanc (1998) indicates that problem solving is an acquired skill; the more students practice it, the better they get. A good alternative for including problem-solving skills in the curriculum is to incorporate it in an introductory engineering course for freshmen. References $[2,11,15]$ all discuss the need for an introductory engineering course that provides hands-on, team-oriented, project-based design experience for engineering freshmen. They recommend that an introductory course be taught in a number of sections, each involves a different engineering department so that students are exposed to the different departments in the engineering college. 
The purpose of this paper is to discuss the redesign and integration of active and cooperative learning techniques within a first-year introductory engineering course specific to industrial engineering. In the following section, we briefly discuss how the previous course was structured and discuss the new structure that incorporates active and cooperative learning exercises. We then present and discuss examples of the active and cooperative learning materials specifically developed for the introductory industrial engineering course. Finally, we discuss the use of projects within the course and wrap up with some concluding remarks concerning our experiences with these methods.

\section{Overview of the Course}

For industrial engineering students at the University of Arkansas, courses normally taken during the first year constitute the pre-professional curriculum that includes Calculus I and II, Chemistry I, English Composition I and II, and Principles of Industrial Engineering. Satisfactory completion of the pre-professional curriculum is a prerequisite for enrollment in any 2000-level or higher engineering course. The course has contained between 80 and 100 students over the last few offerings and is divided into a group lecture component and individual drill sections containing around 20 students each. In the past, the course has relied heavily on lecture supported by hands on laboratory/drill sections. The material in lecture was often a survey of topics in Industrial Engineering delivered in a standard lecture format. In addition, the lecture included curriculum advising, faculty introductions, and study skill development. Drill or problem sections allowed the students to work on computer-based skills, cover homework topics, and provided exam review support.

Based on feedback from our ABET review processes, we decided that the current structure of the course was not quite addressing all of our program objectives. Our program objectives attempt to:

1. Educate students in core IE fundamentals.

2. Develop students who demonstrate written/oral, teamwork, and professional skills.

3. Develop students who can design, improve, and manage integrated systems.

4. Develop students who can model and solve unstructured problems.

5. Develop students who value and can pursue life-long learning.

While the past format adequately addressed content, especially for the first objective, we felt that we could enhance the students experience during the first year by concentrating more on objectives two through four, especially problem solving skills. In addition, we have spent considerable effort on improving the recruiting of our students, see Gattis et al. (2003) and wanted the first course to assist with retention through a more active experience.

The course was redesigned to achieve the following outcomes for the students:

- An ability to use introductory problem solving on core topics of Industrial Engineering, including probability and statistics, ergonomics, engineering management, operations research, manufacturing, and logistics. 
- An ability to use basic software packages, such as word processing, spreadsheets, presentation graphics, database software, email, web authoring tools, and Internet browsers.

- An ability to be an effective team member.

- An understanding of what it means to be a professional and ethical student and engineer.

- An ability to document laboratory work, and to communicate work in a quality and professional report.

- An awareness and understanding of ABET and the Industrial Engineering curriculum.

The course presents introductory coverage of the following topics: engineering problem solving, systems analysis, mathematical modeling with spreadsheets, gathering and reporting data with statistics, elementary quality control, elementary forecasting and inventory control, basic manufacturing processes and manufacturing systems, engineering management concepts, work method concepts, and an introduction to information modeling/databases.

The development of problem solving and modeling skills is a key component of the course. The course concentrates on developing problem solving skills in the students by teaching them to formulate and solve basic engineering problems, apply basic industrial engineering techniques, and how to analyze and use models. We begin by teaching them how to apply a simple problem solving strategy to engineering situations. The problem solving strategy follows the DEGREE pattern invented by one of the authors. DEGREE stands for:

- Define the problem.

- Establish performance criteria.

- Generate alternative solutions.

- Rank the solutions according to the criteria.

- Evaluate the problem solving process and the solution.

- Execute the solution.

This pattern follows some of the well known techniques that have been developed and applied to first-year engineering general engineering courses. See for example Fogler and LeBlanc (1995). In addition to general problem solving, we introduce students to specific engineering problems faced by industrial engineers. We want the students to be able to:

- List and identify the functions of an industrial engineer.

- Describe and explain the role of an industrial engineer within an enterprise.

- Describe the typical applications or problems addressed by industrial engineers.

- Solve introductory problems within industrial engineering such as break-even analysis, quality control charts, economic order quantities, manufacturing planning, project management, engineering economics, transportation planning, and information systems.

Finally, the course emphasizes how to understand and use models. In particular, students are introduced to different types of models (e.g. conceptual, pictorial, analytical, etc.) They are asked to create and interpret pictorial models (goal tree, process flowchart, influence diagram, precedence diagram, entity-relationship diagram, etc.). In addition, they are shown basic IE 
models such as EOQ, present worth, etc. and asked to use the models. They are also asked to evaluate the quality of models, perform sensitivity analysis, and implement models within a spreadsheet.

To support the new course structure, we have developed active learning materials that support many of the topics given above. These materials are used within lecture and then within drill sections. In the following sections, we will discuss examples of the materials used within the course.

\section{Examples of Active Learning Exercises}

Since the course is an introduction to engineering and to industrial engineering in particular, the activities that were developed needed to support future course work by the students. Table 1 presents the activities developed to provide a brief introduction to required IE courses for an industrial engineering student.

Table1. Activities for Introduction to IE

\begin{tabular}{|l|l|}
\hline \multicolumn{1}{|c|}{ Course Name } & \multicolumn{1}{c|}{ Activity Name } \\
\hline INEG 1403 Industrial Cost Analysis & Inventory \\
\hline INEG 3313 Engineering Statistics & Gathering and Reporting Data \\
\hline INEG 3413 Engineering Econ Analysis & Engineering Economy \\
\hline INEG 3513 Manufacturing Systems Design & Manufacturing Processes \\
\hline INEG 3713 Methods and Standards & Learning Curves \\
\hline INEG 4323 Quality Engr and Management & Quality Control \\
\hline INEG 4543 Materials Handling & Material Handling \\
\hline INEG 4553 Production/Planning Control & Basic Forecasting \& Manufacturing Systems \\
\hline
\end{tabular}

Based on our prior experience using active learning methods, we recommend that activities be supported by a handout. For small activities, we recommend the following format:

- Objective of the Activity: Describe what the students should achieve by successfully completing the activity

- Setup: A description of what the students should know in order to do the activity, instructions for forming the groups, instructions for performing the activity, and general overview of what to record for the activity.

- Activity: Detailed instructions and materials that allow the students to complete the activity. For example, if the activity is a problem solving activity then the problem would be placed here.

- Accountability: Instructions for how the students will be made accountable. For example, one student from the group will be randomly selected and asked to report the group's solution.

- Follow up: If applicable, instructions for how the students can expand on the activity. 
For longer activities, instructions for homework based on the activity would be appropriate here.

For more complicated topics, we suggest that the handout incorporate the lecture material from the mini-lectures. The handout should contain definition of new terms, formulas, examples of problems, and a detailed description of the student activity. The handouts should be designed so that students will not need other resources to do the activities.

For the sake of space, we have only included two examples of the handout activities; one for quality control and one for manufacturing systems. As one can see from the exhibits, detailed information is given in the handout, with an example. The topic is introduced and a "standard" lecture ensues. Then, the class is asked to form into groups. Alternatively, you might randomly assign them into groups. The groups are asked to read the handout. At this stage it is useful to ask for questions on the material. After any questions are handled, the students are asked to begin the activity. The professor should visit the groups as they process the activity, clarifying any questions, keeping them on track, and monitoring the solutions being developed. Then, a group should be selected to present their results to the class. While some collaborative learning literature suggests that the group be selected at random, we recommend that the instructor be fairly sure that the group has a viable answer (through the monitoring process) before presenting the results. Randomly selecting the presenter from the group is important to ensure that interdependence forms.

The course also includes a team design project. We solicited example project ideas from the IE community. In the fall 2001, the course project was based on the Tiger Air, Inc Case Study (by C. R. Sox (csox@cba.ua.edu). This case study involves the design of a paper airplane manufacturing system that includes selecting a design based on quality and cost considerations, developing a workstation to "manufacture" the airplanes, manufacturing the planes, and flight testing the planes. The students worked in groups of 5-7 on the project and had to write a project report as well as give an oral presentation of their work. The quality and energy associated with the projects was remarkable. Most groups used time study, Excel, cost estimating, quality testing (statistical data collection), and material used within the course. Teamwork is emphasized in this course to excite the students about engineering, to help in retention, and to develop team and problem solving skills. Since then, we have developed a similar project based on the assembly of LEGO cars. In this project, the students must make a bill of materials, product assembly instructions, give a workstation layout, complete a time study, and discuss economic and ergonomic issues. More details of this project as well as other exhibits, including a packet of the materials, will be discussed and available at the 2003 ASEE Conference.

\section{Concluding Remarks}

Initial prot otypes of the activities were utilized within the fall 2002 offering of the course. The use of the full set of materials is targeted during the fall 2003 offering. The initial response by students was positive during the fall of 2002. They indicated a preference for the hands-on activities, although no formal data was collected. A small student preference evaluation of the 
materials is planned for the next offering of the course. The project (Tiger Air, Inc.) was met with great enthusiasm during the fall of 2001. Students committed their time and produced outstanding results. On a number of occasions upper level students commented that they wish that they had had such opportunities during the time when they took the course.

Our change for this course is consistent with other disciplines' experience with these methods. For example, at the Carnegie Mellon University, the seven principles for good practice in undergraduate education include active learning, as well as student-faculty contact. Ambrose and Amon (1997) discuss their successes in the implementation of active learning into the design a first-year mechanical engineering course by integrating lectures with classroom demonstrations, laboratory experiments, and hands-on projects. As claimed by the authors, actively engaging students in a classroom activity is vital to learning. The instructor should provide opportunities for interaction during lectures and outside of class, using demonstrations and hands-on projects to stimulate students' interest. Furthermore, students should be given the chance to practice because time on task enhances learning, as indicated by several studies on learning that students learn by doing.

We feel that the use of active and collaborative techniques within introductory engineering courses is essential in helping students transition into engineering. The group work fosters a natural support mechanism that improves student learning and motivation. These techniques are especially helpful at the introductory level because student can get "hands on" experience with topics and concepts that are very new to them. When using these techniques, we recommend that instructors mentally prepare students by discussing the technique with them and make sure that the students fully understand the expectations concerning the level of participation. To be successful with this technique, instructors must lead the students past their passivity and continually monitor them so that they (and you) do not slip back into the old comfortable lecture mode.

\section{Appendix}

\section{Exhibit 1: Quality Control Activity}




\section{What is Quality?}

- Transcendent definition: Innate excellence

- Product-based definition: The more the better

- User-based definition: What the customer wants

- Manufacturing-based definition: Conformance to design specification

- Value-based definition: Affordable excellence

\section{Control Charts}

When dealing with a quality characteristic that can be expresses as a measurement, it is customary to monitor both the mean value of the quality characteristic and its variability. The $\bar{X}$ and $R$ control charts are used together in analyzing a single measurable characteristic.

\section{Building Control Charts}

1. Collect samples ( $m=$ number of subgroups) from the process

- Equally spaced in time

- $n=$ sample size

- Measure the quality of each item in the sample

2. For each sample, compute:

- The sample mean, $\bar{X}$ (average)

- $\quad$ The sample range, $R(\max -\min )$

3. Compute:
- $\quad$ Overall mean $=\overline{\bar{X}}$

Average of the sample ranges $=\bar{R}$
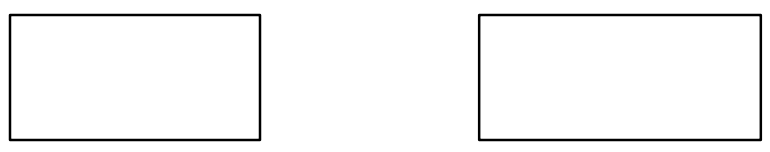


\section{Example 1}

A component part for a jet aircraft engine is manufactured by an investment casting process. The vane opening on this casting is an important functional parameter of the part. This example illustrates the use of $\bar{X}$ and $R$ control charts to assess the statistical stability of this process. Table 1 presents 20 samples $(m=20)$ of five parts each $(n=5)$.

The table represents the last three digits of the dimensions.

The formula for the overall mean, $\overline{\bar{X}}$, and the average of the sample ranges, $\bar{R}$, are given below:

$$
\overline{\bar{X}}=\frac{1}{m} \sum_{i=1}^{m} \bar{X}_{i} \quad \bar{R}=\frac{1}{m} \sum_{i=1}^{m} R_{i}
$$

The center line and upper and lower control limits for an $\bar{X}$ control chart are

$U C L=\overline{\bar{X}}+A_{2} \bar{R}$

$\mathrm{CL}=\overline{\bar{X}}$

$L C L=\overline{\bar{X}}-A_{2} \bar{R}$

where the constant $A_{2}$ is tabulated for the various sample sizes in Table 2.

The center line and upper and lower control limits for an $R$ chart are

$U C L=D_{4} \bar{R}$

$C L \quad=R$

$L C L \quad=D_{3} \bar{R}$

Where $\bar{R}$ is the sample average range, and the constants $D_{3}$ and D4 are tabulated for various sample sizes in Table 2 .

\section{Table 1}

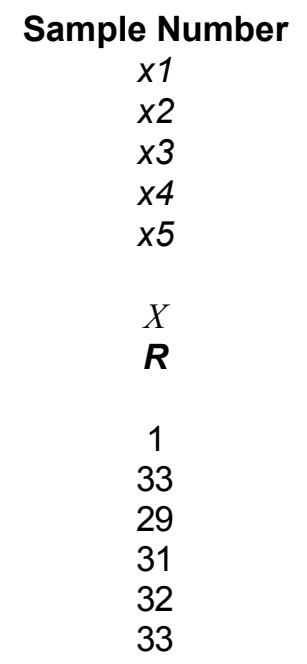

Proceedings of the 2003 American Society for Engineering Education Annual Conference \& Exposition

Copyright $\left({ }_{0}\right.$ 2003, American Society for Engineering Education 


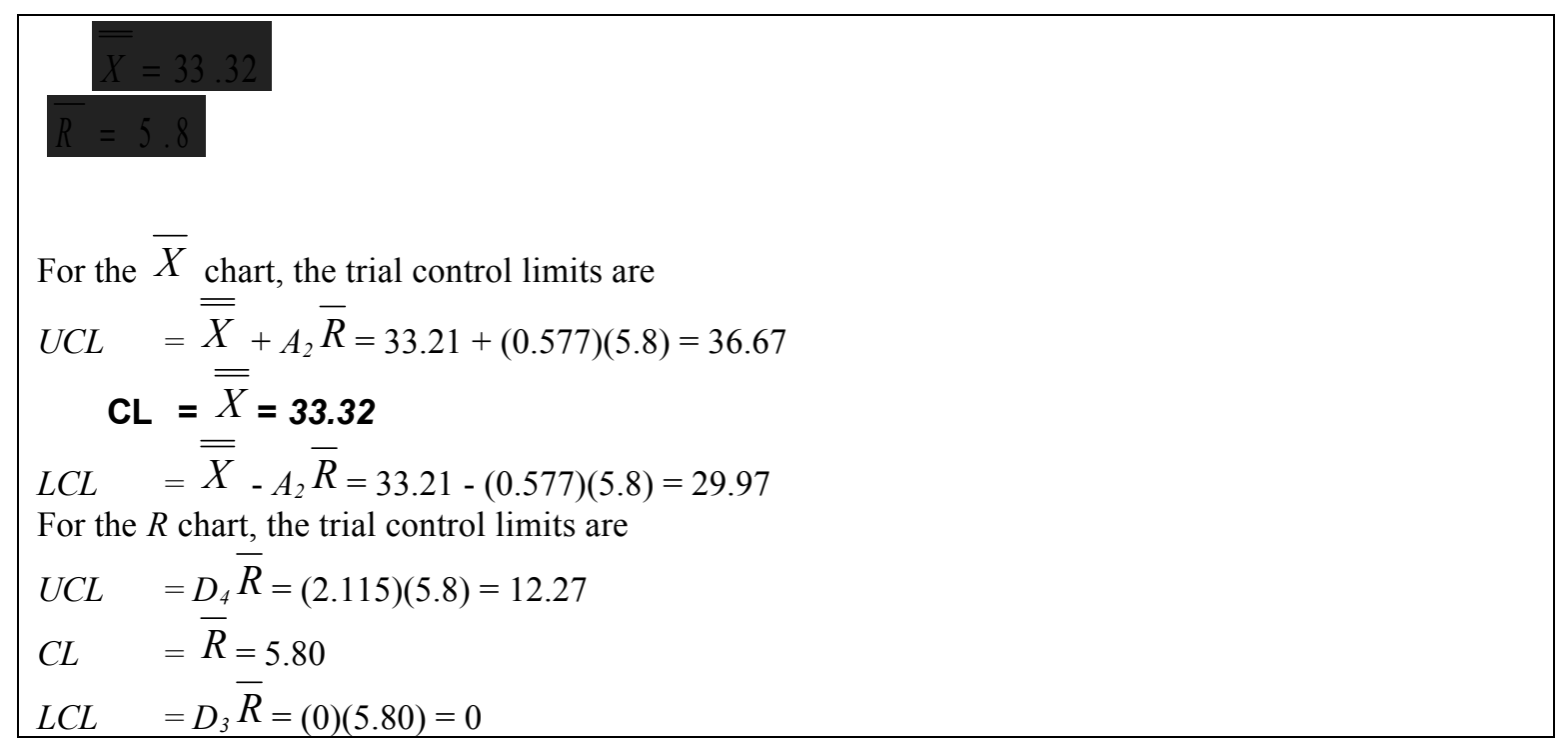


Objective: An introduction to quality control, which involves creating and computing a control chart. Setup: Students should form a group of two.

1. Take 5 minutes to read the problem individually.

2. Take 5 minutes to solve the problem as a group.

3. Compare your group's answer with the answer of a group near you.

4. Record your answer in preparation for presentation to the class.

Activity:

Twenty samples of size 4 are drawn from a process at one-hour intervals, and the following data are obtained.

Observation

Sample
$\mathbf{1}$
$\mathbf{2}$
$\mathbf{3}$
$\mathbf{4}$
$\boldsymbol{X}$-bar
$\boldsymbol{R}$

1
15
10
8
9
10.50
7

2
14
14
10
6
11.00
8

8

3

9

10

9

11

9.75

2

4

8

6

9

13

9.00

7 


\section{Exhibit 2: Manufacturing Systems Activity}

\section{Definitions}

- Workstation: A workstation is a collection of one or more machines or manual stations that perform (essentially) identical functions.

- Part: A part is a piece of raw material, a component, a subassembly, or an assembly that is worked on at the workstations in a plant.

- End item: A part that is sold directly to a customer, whether or not it is an assembly, is called an end item.

- Routing: A routing describes the sequence of workstations passed through by a part.

- Order: A customer order is a request from a customer for a particular part number.

- Job: A job refers to a set of physical materials that traverses a routing, along with the associated logical information.

Factory Performance Metric Definitions

- Throughput (TH): The average number of units produced by a factory per unit of time.

- Work In Process (WIP) Inventory: The inventory between the start and end points of a product routing.

- Cycle Time (CT): The average time from the release of a job at the beginning of the routing until it reaches an inventory point at the end of the routing.

- On-time Delivery: The percent of product delivered on or before the delivery date promised to the customer (due date).

- Yield: The number of good units divided by the number of unit starts for a given period.

- Capacity Utilization: The number of units produced in a particular tool set divided by the maximum number of units that could have been produced during the same time period.

\section{Parameters}

- Bottleneck Rate $\left({ }^{r_{b}}\right)$ : The rate (parts per unit time or jobs per unit time) of the workstation having the highest long-term utilization. The bottleneck rate is simply the rate of the slowest workstation.

- Raw Process Time $\left({ }^{T_{0}}\right)$ : The sum of the long-term average process times of each workstation in the line.

Critical WIP $\left({ }^{W_{0}}\right)$ : The WIP level for which a line achieves maximum throughput (that is, ${ }_{b}$ ) with minimum cycle time (that is, $T_{0}$ ), assuming no variability. Critical WIP is defined by the bottleneck rate and raw process time by the following relationship: $W_{0}=r_{b} \times T_{0}$

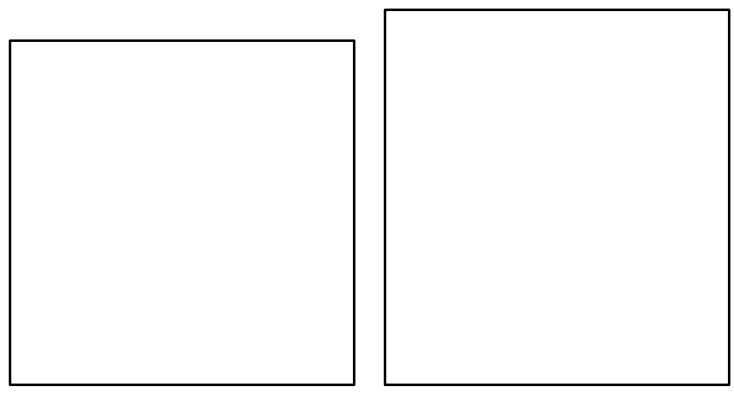

Proceedings of the 2003 American Society for Engineering Education Annual Conference \& Exposition Copyright $@$ (2003, American Society for Engineering Education 


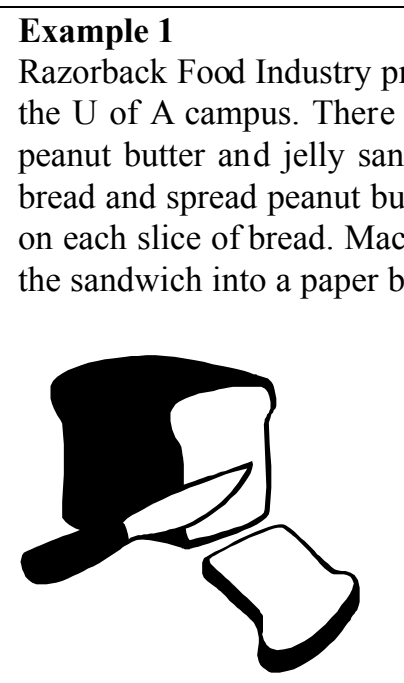

Machine 1

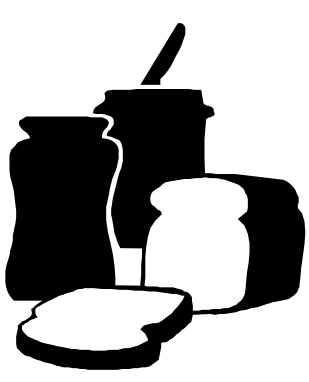

Machine 2

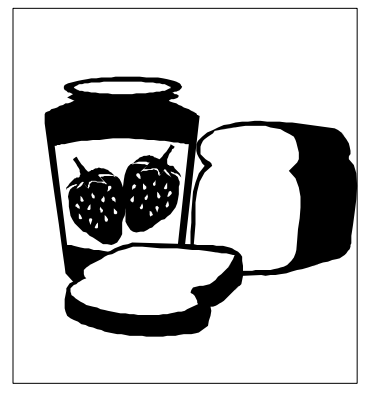

Machine 3

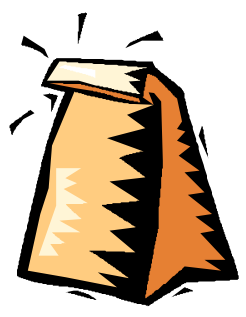

Machine 4

The approximate process time of each machine is given by the table below.

\title{
Station Number \\ Number of Machines \\ Process Time \\ (minute)
}

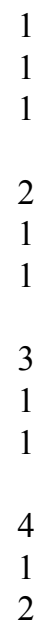

For this problem:

a) Calculate the capacity of each workstation.

b) Identify the bottleneck station and calculate its rate $\left({ }^{r_{b}}\right)$.

c) Calculate the raw process time $\left({ }^{T_{0}}\right)$.

d) Calculate the critical WIP $\left({ }^{W_{0}}\right)$ level for this production line.

\section{Solution}

a)

\author{
Station Number \\ Number of Machines \\ Process Time \\ (minute) \\ Station Capacity \\ (Jobs per Minute)
}


Objective: To introduce the concept of workstation's capacity, bottleneck rate and raw material process time. Setup: Students should Students should form a group of two.

1. Take 5 minutes to read the problem individually.

2. Take 5 minutes to solve the problem as a group.

3. Compare your group's answer with the answer of a group near you.

4. Record your answer in preparation for presentation to the class.

\section{Activity:}

The Hog Stationary Company manufactures envelopes in its plant. The line consists of 4 workstations. The number of machines on each workstation and its process time is given in the table below.

\section{Station Number Number of Machines \\ Process Time (minute)}

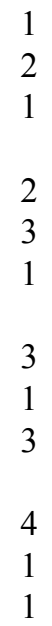

Workstation 1 cuts paper into the shape of envelope, workstation 2 applies glue to the paper, workstation 3 folds the paper into envelopes, and, finally, workstation 4 puts the envelopes into small boxes.

For this problem:

a) Calculate the capacity of each workstation.

b) Identify the bottleneck station and calculate its rate.

c) Calculate the raw process time $\left(T_{0}\right)$.

d) Calculate the critical WIP ( ${ }^{W_{0}}$ ) level for this production line.

Accountability: Randomly select 1 group of students and then randomly select 1 person from a group to place solution on the board and to explain their answer. (5 minutes)

\section{Bibliography}

1. Ambrose, S. A. and Amon, C. H. (1997) "Systematic Design of a First-Year Mechanical Engineering Course at Carnegie Mellon Univeristy," Journal of Engineering Education, April 1997,173-181

2. Clough, D. E. (2002) "A modern computing course with emphasis on problem solving and programming", 2002 American Society of Engineering Education Conference and Exposition, Montréal, Quebec Canada.

3. Felder, R. M. Resources In Science And Engineering Education, http://www2.ncsu.edu/unity/lockers/users/f/felder/public/RMF.html

4. Felder, R.M., Felder, G.N., and Dietz, E.J. (1998) "A Longitudinal Study of Engineering Student Performance and Retention. V. Comparisons with Traditionally-Taught Students”, Journal of Engineering Education, 87(4), 469-480

5. Fogler, H. S. and LeBlanc, S. E. 1995. Strategies for Creative Problem Solving, Prentice-Hall. 
6. Johnson, D., R. Johnson, and K. Smith. 1998. "Cooperative Learning Returns to College: What evidence is there that it works?", Change, July/August, pp. 27-35

7. Gattis, C., Nachtmann, H., and Youngblood, A., (2003) "The Students-Recruiting-Students Undergraduate Engineering Recruiting Program," to appear in the European Journal of Engineering Education, Vol. 28, No. 1.

8. LeBlanc, S. E. (1998) "Some thoughts on teaching problem solving skills to engineering students", 2000 American Society of Engineering Education Conference and Exposition, St. Louis, MO.

9. Rossetti, M. D., and Nembhard, H. (2000) "Using Active and Collaborative Learning in Industrial Engineering Education”, 2000 American Society of Engineering Education Conference and Exposition, St. Louis, MO.

10. Rossetti, M. D., and Nembhard, H. (1998) "A Tutorial on Active and Collaborative Learning in Simulation Education", The Proceedings of the 1998 Winter Simulation Conference, ed. D. J. Medeiros, E. F. Watson, J. S. Carson, M. S. Manivannan, ACM/SIGSIM, ASA, IEEE/CS, IEEE/SMCS, IIE, INFORMS/CS, NIST and SCS, pp. 67-74.

11. Rossetti, M. D. (1997) "Activate This Classroom at Time Now," in The Proceedings of the 1997 Winter Simulation Conference, ed. S. Andradottir, K. J. Healy, D. H. Withers, and B. L. Nelson, ACM/SIGSIM, ASA, IEEE/CS, IEEE/SMCS, IIE, INFORMS/CS, NIST and SCS, pp. 1383-1389

12. Ruggles, R. (2000) "A first year introductory engineering course with a design component", 2000 American Society of Engineering Education Conference and Exposition, St. Louis, MO.

13. Smith, K. 1993. "Designing a first year engineering course", In Design Education in Metallurgical and Materials Engineering, edited by M. E. Schlesinger and D. E. Mikkola, The Minerals, Metals, \& Materials Society.

14. Smith, K. Strategies for Energizing Large Classes: From Small Groups to Learning Communities Web Resources, http://www.ce.umn.edu/ smith/ndtlcl/weblinks.html

15. Starfield, A. M., Smith, K. A., and Bleloch, A. L. 1994. How to model it: Problem solving for the computer age. Edina, MN: Burgess International Group, Inc.

16. Yost, S. A. (2000) "Introducing mechatronics in a first-year intro to engineering design course", 2000 American Society of Engineering Education Conference and Exposition, St. Louis, MO.

MANUEL D. ROSSETTI

Manuel Rossetti is an Assistant Professor in the Industrial Engineering Department at the University of Arkansas. He received his Ph.D. in Industrial and Systems Engineering from The Ohio State University. Dr. Rossetti has published over twenty-five journal and conference articles in the areas of transportation, manufacturing, health care and simulation. He was selected as a Lilly Teaching Fellow in 1997/98 and has been twice nominated for outstanding teaching awards. He is currently serving as Departmental ABET Coordinator. He serves as an Associate Editor for the International Journal of Modeling and Simulation and is active in IIE, INFORMS, ASEE, and SCS.

\section{MERRISA PURNOMO}

Merrisa Purnomo is an undergraduate research assistant in the Department of Industrial Engineering at the University of Arkansas. She is actively involved in a number of student organizations, and she serves as the treasurer of Alpha Pi Mu Industrial Engineering Honor Society in the academic year 02-03. Merrisa Purnomo was selected as a recipient of Porter Stone Award based on her academic and professional (co-op) achievements, and she recently won the Hytrol Challenge Design Award. 